Supporting information

\title{
Visualization of the Distance Among Fishes by MALDI MS for Rapid Determination of the Taxonomic Status of Fish Fillets
}

Chengyu Wang, Hongyan Bi*, Jing Xie

College of Food Science and Engineering, Shanghai Ocean University, Hucheng Ring Road 999, Pudong New District, 201306 Shanghai, China

* To whom correspondence should be addressed. E-mail address: hybi@shou.edu.cn

E-mail address for the other authors: E-mail address for the other authors:

wangchengyu1002@163.com; jxie@shou.edu.cn 


\section{S1. Size and weight of the seafood samples studied in the present work}

Table S1. Size and weight of seafood samples analyzed in the present study. Salmo salar (SS) sample was obtained as fillet, and the size and weight of the whole fish samples are not available (N/A).

\begin{tabular}{lllll}
\hline $\begin{array}{l}\text { sample } \\
\text { No. }\end{array}$ & fish species & $\begin{array}{l}\text { biological } \\
\text { replicates }\end{array}$ & size / cm & weight / g \\
\hline 1 & Brama japonica (BJ) & 6 & $18.9 \pm 0.9$ & $113.0 \pm 11.4$ \\
\hline 2 & Trachinotus ovatus (TO) & 6 & $23.8 \pm 8.9$ & $248.0 \pm 5.0$ \\
\hline 3 & Larimichthys crocea (LC) & 6 & $32.2 \pm 1.1$ & $425.8 \pm 17.4$ \\
\hline 4 & Larimichthys polyactis (LP) & 6 & $17.3 \pm 0.4$ & $53.3 \pm 14.3$ \\
\hline 5 & Oncorhynchus aguabonit (OA) & 6 & $38.5 \pm 3.3$ & $895 \pm 8.2$ \\
\hline 6 & Oncorhynchus mykiss (OM) & 6 & $37.6 \pm 3.6$ & $897 \pm 131.4$ \\
\hline 7 & Salmo salar (SS) & 6 pieces & N/A & ca. 200g/ piece \\
\hline 8 & Culter alburnus (CA) & 6 & $24.2 \pm 1.5$ & $81.7 \pm 14.6$ \\
\hline 9 & Pseudaspius leptocephalus (PL) & 6 & $24.5 \pm 0.7$ & $79.2 \pm 10.2$ \\
\hline 10 & Zeus faber (ZF) & 6 & $29.8 \pm 1.2$ & $292.5 \pm 12.1$ \\
\hline 11 & Pampus argenteus (PA) & 6 & $22.2 \pm 1.8$ & $117.5 \pm 0.5$ \\
\hline 12 & $\begin{array}{l}\text { Charybdis japonica (CJ) } \\
\text { (crab) }\end{array}$ & 6 & N/A & N/A \\
\hline 13 & $\begin{array}{l}\text { Portunus trituberculatus (PT) } \\
\text { (crab) }\end{array}$ & 6 & N/A & N/A \\
\hline
\end{tabular}


S2. Similarity in texture of muscle tissues of closely related fishes
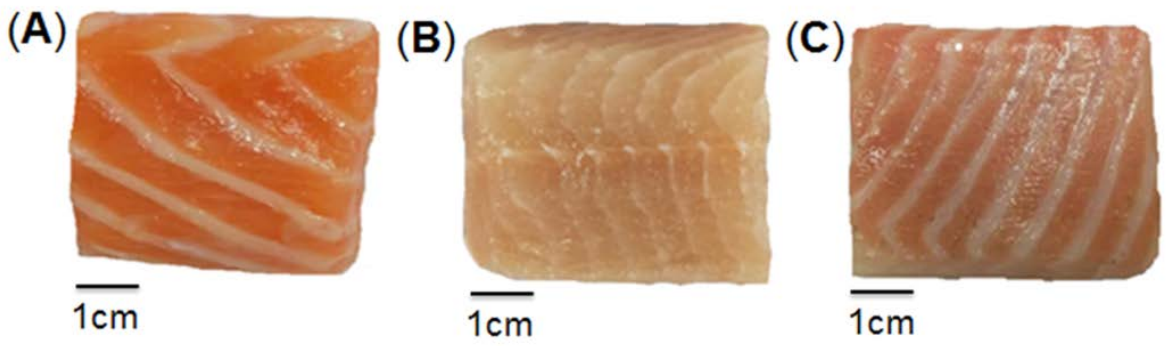

Figure S1. The photos of the fillet samples of fish (A) salmon (Salmo salar), (B) golden trout (Oncorhynchus aguabonita), and (C) rainbow trout (Oncorhynchus mykiss). The photos were taken under natural daylight. 


\section{S3. Impact of matrix for mass spectra}

Matrix can affect the quality of mass spectral patterns for matrix-assisted laser desorption/ionization mass spectrometry (MALDI MS) analysis. ${ }^{1}$ To obtain high-quality mass spectra, sample preparation procedure was taken into account. $\alpha$-Cyano-4-hydroxycynnamic acid (CHCA) and sinapinic acid (SA) are widely-used matrices for biological analysis. ${ }^{2}$ SA can be applied for peptides, large proteins and lipids analysis, while CHCA can be applied for peptides, small proteins and glycopeptides analysis. ${ }^{3}$

In the present report, the fish fillet samples from fish Larimichthys crocea (LC) were taken as models to compare the mass spectra when using CHCA and SA as matrix, respectively. Figure S2 shows the averaged mass spectra of the obtained mass spectra where fillet samples of LC were processed and analyzed under the matrix of CHCA and SA, respectively. It can be found that CHCA can assist to obtain more satisfactory mass spectra than SA when considering the signal intensity and the peaks yield in the mass range of 2000 to 10000 Da. CHCA was thus selected for performing the MALDI MS experiments for the analysis of the extracts of other fish fillet samples.

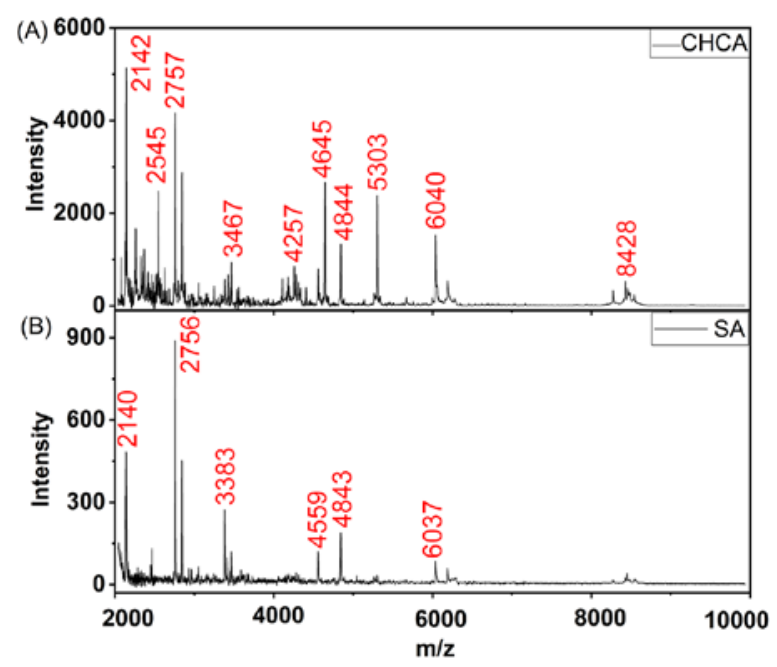

Figure S2. Averaged mass spectra for processed samples of fillets of fish species Larimichthys crocea (LC) when using matrix $\alpha$-cyano-4-hydroxycynnamic acid (CHCA) and sinapinic acid (SA), respectively. 


\section{S4. Comparison of mass spectra for protein extracts of muscle tissues from different parts}

of fish

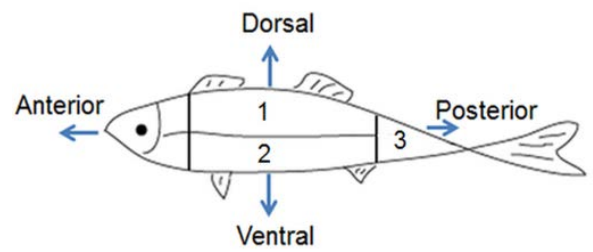

Figure S3. Illustration of the different parts obtained from fish samples. 1: dorsal part; 2: ventral part; 3 posterior part.

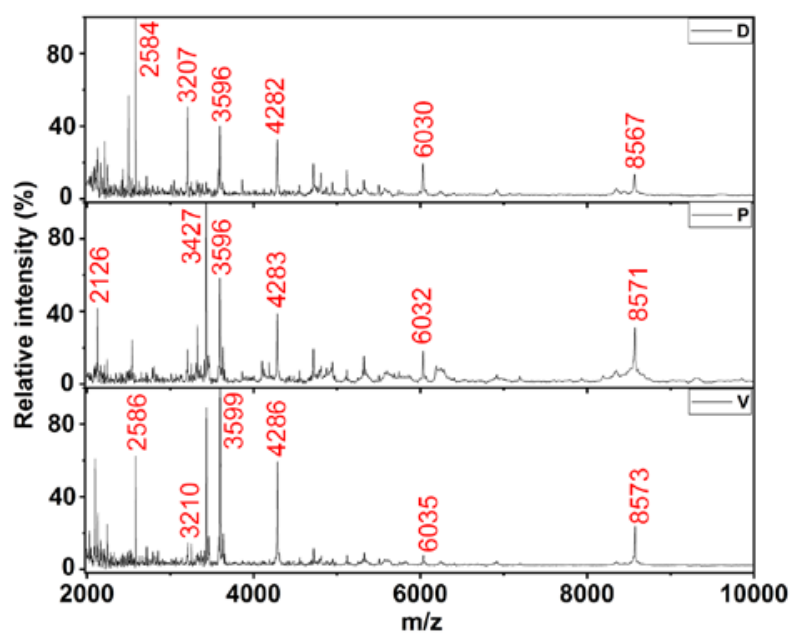

Figure S4. Averaged MALDI mass spectra of three parts of one fish species. Fish species Larimichthys crocea (LC) was studied as a model, which dorsal (D), ventral (V), and posterior (P) parts of muscle were taken for performing matrix-assisted laser desorption/ionization mass spectrometry (MALDI MS) analysis. Six mass spectra were obtained for each part. 


\section{S5. Mass spectral data for each fish species}
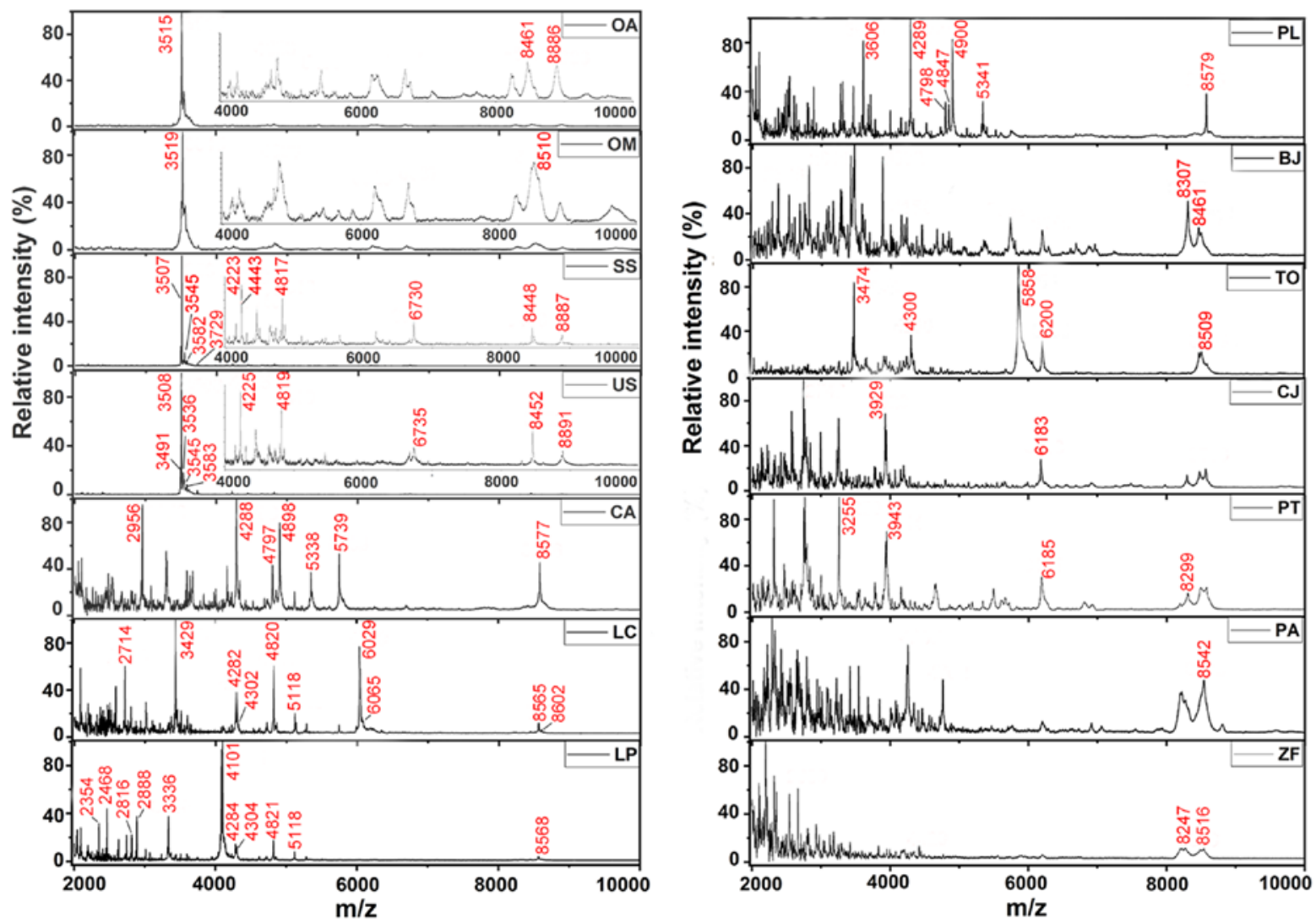

Figure S5. Averaged mass spectra of analyzed fish species, including Oncorhynchus aguabonita (OA), Oncorhynchus mykiss (OM), Salmo salar (SS), Brama japonica (BJ), Trachinotus ovatus (TO), Larimichthys crocea (LC), Larimichthys polyactis (LP), Culter alburnus (CA) and Pseudaspius leptocephalus (PL), Pampus argenteus (PA), Zeus faber (ZF), Charybdis japonica (CJ), Portunus trituberculatus (PT), and unknown fish sample (US). The muscle extracts of fish samples were analyzed by MALDI MS. 18 mass spectra were normally obtained for each fish species. Note that not all the peaks are labeled with $\mathrm{m} / \mathrm{z}$ in the inlet. 
Table S2. Numbers of peaks with signal-to-noise ratio $(\mathrm{SNR}) \geq 3$, and list of mass peaks with $\mathrm{SNR} \geq 10$ of the analyzed fish species.

\begin{tabular}{|c|c|c|}
\hline fish species & $\begin{array}{l}\text { number of } \\
\text { peaks with } \\
\mathrm{S} / \mathrm{N} \geq 3\end{array}$ & $\begin{array}{l}\text { mass peaks with } \mathrm{S} / \mathrm{N} \geq 10 \text { in } \\
\text { the averaged mass spectra } \\
\text { (averaged } \mathrm{m} / \mathrm{z} \pm \text { standard } \\
\text { deviation }(\mathrm{SD}) \text { ) }\end{array}$ \\
\hline Brama japonica (BJ) & $29 \pm 5(n=18)$ & $8307 \pm 3,8461 \pm 4$ \\
\hline $\begin{array}{l}\text { Trachinotus ovatus } \\
\text { (TO) }\end{array}$ & $48 \pm 9(n=16)$ & $\begin{array}{l}3474 \pm 1,4300 \pm 2,5858 \pm 3 \\
6200 \pm 3,8509 \pm 3\end{array}$ \\
\hline $\begin{array}{l}\text { Larimichthys crocea } \\
\text { (LC) }\end{array}$ & $33 \pm 8(n=18)$ & $\begin{array}{l}2714 \pm 1,3429 \pm 1,4282 \pm 1, \\
4302 \pm 1,4820 \pm 1,5118 \pm 1, \\
6029 \pm 2,6065 \pm 2,8565 \pm 2, \\
8602 \pm 1\end{array}$ \\
\hline $\begin{array}{l}\text { Larimichthys } \\
\text { polyactis (LP) }\end{array}$ & $42 \pm 7(n=18)$ & $\begin{array}{l}2354 \pm 1,2468 \pm 1,2816 \pm 1, \\
2888 \pm 1,3336 \pm 1,4101 \pm 1, \\
4284 \pm 1,4304 \pm 1,4821 \pm 1, \\
5118 \pm 1,8568 \pm 2\end{array}$ \\
\hline $\begin{array}{l}\text { Oncorhynchus } \\
\text { aguabonit (OA) }\end{array}$ & $34 \pm 6(n=18)$ & $3515 \pm 2,8461 \pm 5,8886 \pm 4$ \\
\hline $\begin{array}{l}\text { Oncorhynchus } \\
\text { mykiss (OM) }\end{array}$ & $35 \pm 6(n=18)$ & $3519 \pm 1,8510 \pm 3$ \\
\hline Salmo salar (SS) & $27 \pm 5(n=18)$ & $\begin{array}{l}3507 \pm 1,3545 \pm 1,3582 \pm 1, \\
3729 \pm 1,4223 \pm 1,4443 \pm 1, \\
4817 \pm 1,6730 \pm 1,8448 \pm 2, \\
8887 \pm 2\end{array}$ \\
\hline $\begin{array}{l}\text { Culter alburnus } \\
\text { (CA) }\end{array}$ & $21 \pm 7(n=18)$ & $\begin{array}{l}2956 \pm 2,4288 \pm 2,4797 \pm 1, \\
4898 \pm 2,5338 \pm 2,5739 \pm 1, \\
8577 \pm 2\end{array}$ \\
\hline $\begin{array}{l}\text { Pseudaspius } \\
\text { leptocephalus (PL) }\end{array}$ & $39 \pm 8(n=15)$ & $\begin{array}{l}3606 \pm 1,4289 \pm 1,4798 \pm 1 \\
4847 \pm 2,4900 \pm 1,5341 \pm 2 \\
8579 \pm 2\end{array}$ \\
\hline Zeus faber (ZF) & $21 \pm 5(n=18)$ & $8247 \pm 5,8516 \pm 7$ \\
\hline $\begin{array}{l}\text { Pampus argenteus } \\
\text { (PA) }\end{array}$ & $26 \pm 7(n=18)$ & $8542 \pm 2$ \\
\hline $\begin{array}{l}\text { Charybdis japonica } \\
\text { (CJ) (crab) }\end{array}$ & $25 \pm 3(n=9)$ & $3929 \pm 3,6183 \pm 3$ \\
\hline $\begin{array}{l}\text { Portunus } \\
\text { trituberculatus (PT) } \\
\text { (crab) }\end{array}$ & $22 \pm 4(n=9)$ & $\begin{array}{l}3255 \pm 1,3943 \pm 1,6185 \pm 1 \\
8299 \pm 2\end{array}$ \\
\hline $\begin{array}{l}\text { unknown fish } \\
\text { sample (US) }\end{array}$ & $24 \pm 6(n=15)$ & $\begin{array}{l}3491 \pm 1,3508 \pm 1,3536 \pm 2, \\
3545 \pm 1,3583 \pm 1,4225 \pm 1, \\
4819 \pm 2,6735 \pm 1,8452 \pm 1, \\
8891 \pm 1\end{array}$ \\
\hline
\end{tabular}


S6. Cross validation (CV) for the mass spectra of fishes belonging to a same order, family genus and species, respectively
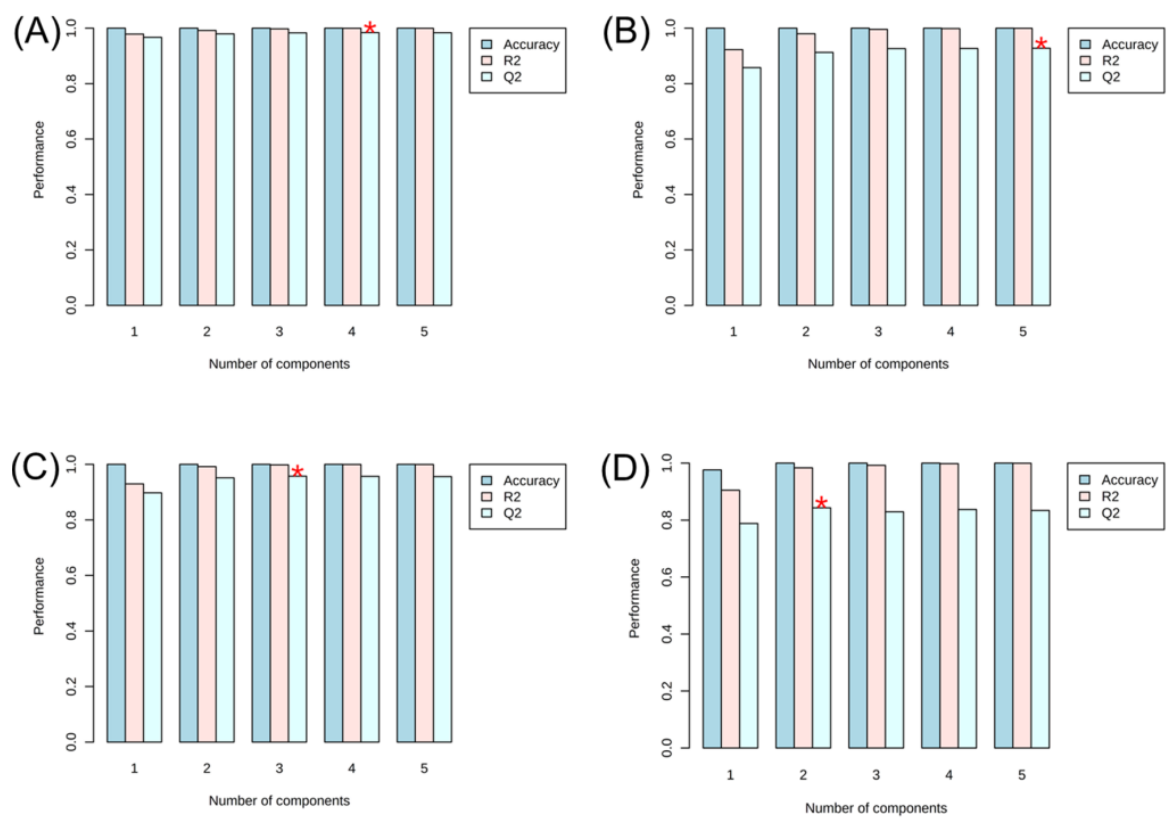

Figure S6. Cross validation (CV) results of the datasets collected from fish species that belong to a same order, family, genus and species, respectively. During modeling, 10-fold CV was used to choose the number of components, where five components were set. $\mathrm{Q}^{2}$ is an estimate of the predictive ability of the model. In each CV plot, the predicted data are compared with the original data, and the sum of squared errors is calculated. The prediction error is then summed over all samples, which is predicted residual sum of squares (short as PRESS). For convenience, the PRESS is divided by the initial sum of squares and subtracted from 1 to resemble the scale of the $\mathrm{R}^{2}$ which provides a measure of model fit to the original data. The analyzed fish samples include: (A) at the order level, Brama japonica (BJ) and Trachinotus ovatus (TO); (B) at the family level, Culter alburnus (CA) and Pseudaspius leptocephalus (PL); (C) at the genus level, Larimichthys crocea (LC) and Larimichthys polyactis (LP); (D) at the species level, Oncorhynchus aguabonita (OA) and Oncorhynchus mykiss (OM). 


\section{S7. Fish authentication by treemaps}

Figure S7(A) shows a tree diagram of the studied fish sample and unknown sample (US) calculated by using Pearson correlation method on the MetaboAnalyst on-line platform. Figure S7(B) shows a tree diagram calculated by using the cosine correlation method listed on the BacteriaMS on-line platform and averaged mass spectral data of the fishes studied in the present study. It can be found that US is from the fish species, SS, which keeps consistent with the genetically tested result.
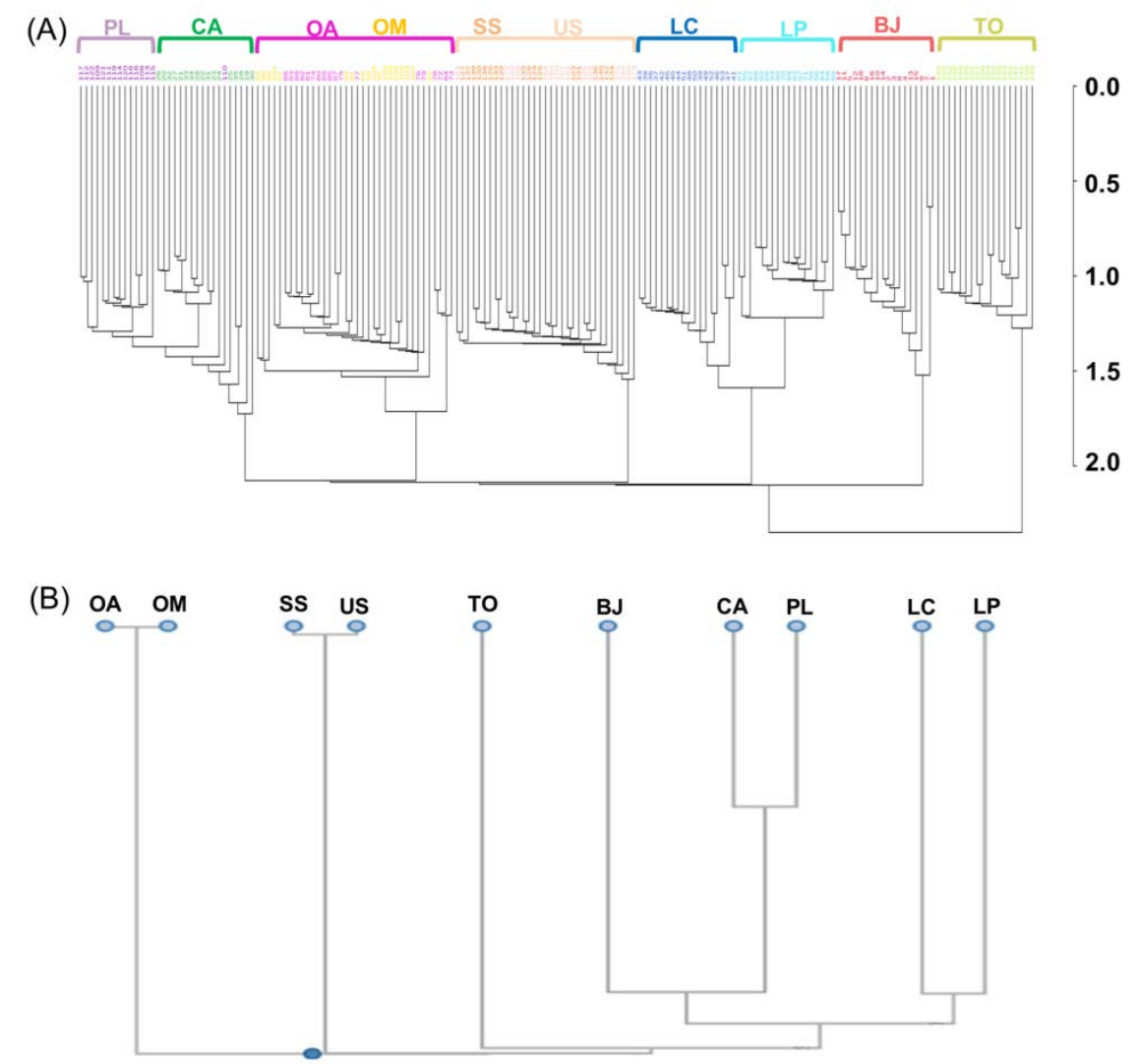

Figure S7. (A) A tree diagram calculated by using Pearson correlation method on https://www.metaboanalyst.ca/ and mass spectral data of unknown fish sample (US) and mass spectral data of fish samples studied in the present study to resolve fish species clusters. The US is obtained from a local restaurant. (B) A tree diagram calculated by using the cosine correlation method on the BacteriaMS on-line platform and averaged mass spectra of the fish samples. The studied fish species include Brama japonica (BJ), Trachinotus ovatus (TO), Larimichthys crocea (LC), Larimichthys polyactis (LP), Oncorhynchus aguabonita (OA), Oncorhynchus mykiss (OM), Salmo salar (SS), Culter alburnus (CA) and Pseudaspius leptocephalus (PL). 


\section{Reference}

1. Gemperline, E.; Rawson, S.; Li, L. Optimization and comparison of multiple MALDI matrix application methods for small molecule mass spectrometric imaging. Anal. Chem. 2014, 86 (20), 10030-10035.

2. Schaiberger, A. M.; Moss, J. A. Optimized sample preparation for MALDI mass spectrometry analysis of protected synthetic peptides. J. Am. Soc. Mass Spectrom. 2008, 19, 614-619.

3. Kaletas, B. K.; van der Wiel, I. M.; Stauber, J.; Lennard, J. D.; Guzel, C.; Kros, J. M.; Luider, T. M.; Heeren, R. M. Sample preparation issues for tissue imaging by imaging MS. Proteomics 2009, 9 (10), 2622-2633. 